DOI10.1590/1807-0191211217

OPCampinasV21N1

\title{
Sentidos de mobilização e de desmobilização da ação coletiva ${ }^{2}$
}

\begin{tabular}{c}
\hline \hline Alcides A. Monteiro \\
Departamento de Sociologia \\
Universidade da Beira Interior - Portugal \\
Mário Miguel Montez \\
Escola Superior de Educação \\
Instituto Politécnico de Coimbra - Portugal \\
\hline \hline
\end{tabular}

Resumo: 0 presente artigo debruça-se sobre o fenómeno da ação coletiva, usando como exemplo a intervenção protagonizada por um pequeno grupo de pessoas em defesa de um espaço de lazer e natureza denominada Mata Nacional do Choupal, situada em Coimbra (Portugal), contra a construção de um viaduto rodoviário. A análise deste pequeno grupo contextualiza a compreensão da relação entre a ação coletiva e o fenómeno da ameaça, mostrando como essa ação coletiva é condicionada por uma dimensão emocional, proveniente da relação do sujeito com os bens de que usufrui. Aponta-se para a existência de uma dinâmica determinante para a mobilização e para a desmobilização da ação coletiva, decorrente da relação entre a ameaça e a perceção de risco pelos elementos do grupo, que denominamos de "sentidos da ação coletiva".

Palavras-chave: ação coletiva; ameaça; risco; mobilização; desmobilização

Abstract: This article focuses on the phenomenon of collective action, using as an example the intervention carried out by a small group of people in defense of a public space of leisure and nature named "Mata Nacional do Choupal", situated in Coimbra (Portugal), against the construction of a highway road. The analysis of this small group frames the understanding of the relationship between collective action and the phenomenon of threat, showing how such collective action is conditioned by an emotional dimension, from the individuals' relation to the goods that they enjoy. Thus, we point out the existence of a dynamic factor for mobilization and demobilization of collective action, arising from the relationship between the threat and the perception of risk by the elements of the group, which we call "directions of collective action".

Keywords: collective action; threat; risk; mobilization; demobilization

\footnotetext{
${ }^{1}$ Esta é uma publicação escrita em português europeu.
} 


\section{Introdução}

O estudo que apresentamos neste artigo incide na relação entre a ação coletiva protagonizada por um pequeno grupo de pessoas e o fenómeno da ameaça, mostrando como a ação coletiva é condicionada por uma dimensão emocional, proveniente, neste caso, da relação de cada sujeito do grupo com os bens de que usufrui. Nesse sentido complementa-se a dimensão de racionalidade da ação coletiva e exploram-se fatores que se relacionam com a perceção de risco dos sujeitos face a uma ameaça sobre esses mesmos bens. Conclui-se que os fatores inscritos na dimensão emocional influem no desenvolvimento da ação coletiva, potencializando tanto a mobilização como a desmobilização de atores para a ação, gerando uma dinâmica constituída por dois sentidos: um sentido ascendente e um sentido descendente da ação coletiva.

O estudo de caso que suporta estas considerações focou-se num grupo de pessoas que, no ano de 2008, se organizaram em defesa de uma área natural e de lazer denominada Mata Nacional do Choupal, situada na cidade de Coimbra, região centro de Portugal. A iminente travessia deste espaço por uma via rodoviária levou à criação de um movimento cívico denominado Plataforma do Choupal². Até 2010 este "pequeno grupo" levou a cabo uma série de atividades socioculturais e de ações judiciais. Em 2010, devido ao conhecimento da anulação do concurso da obra, o movimento desmobilizou-se e a ação coletiva esmoreceu. O estudo de caso realizou-se no centro do processo de desmobilização do movimento.

A análise da ação coletiva promovida pela Plataforma do Choupal conduziu a questionamentos, hipóteses e propostas que aqui se apresentam, originados pelo campo de conflitos que se estende do contexto socioterritorial às dinâmicas internas do grupo, passando por aspetos característicos de modelos de desenvolvimento que se disputam entre si. Do contexto socioterritorial sobressaem conflitos relativos ao usufruto de espaços pelos grupos sociais. Das dinâmicas do grupo relevam-se as forças que impulsionam e que implodem a ação do grupo. No que concerne aos paradigmas de desenvolvimento, destacam-se conflitos ao nível das formas de: governança; valorização de espaços de natureza e lazer e a sua relação com os espaços urbanos; mobilidade pedonal e qualidade de vida versus mobilidade em automóvel e preocupações no sentido "time is money".

Este caso comporta uma complexidade de aspetos orientados pelas energias, motivações, perceções e interesses aliados a emoções dos diversos atores sociais implicados. Por isso, reserva-se um olhar particular sobre a forma como estes fatores afetam as questões políticas e de cidadania nas escalas local e global, no que toca às formas de governança e ao papel dos atores sociais e das ações coletivas pontuais como ponto de partida da construção de movimentos sociais para a transformação social. A sua análise revelou ainda dinâmicas existentes no cerne de um grupo de protesto e da sua ação coletiva que fazem reemergir o debate entre a racionalidade e a emocionalidade da ação coletiva. Por isso, apresenta-se a ação coletiva como conceito envolto no confronto teórico entre estas duas dimensões.

\footnotetext{
2 Disponível em: <http://www.facebook.com/plataforma.choupal>.
} 
MONTEIRO, A. A.; MONTEZ, M. M. Sentidos de mobilização e de desmobilização...

Ação coletiva: contributos teóricos para o debate em torno do conceito

Sendo um comportamento humano, a ação é, para Hanna Arendt, em A condição humana, a "actividade exercida diretamente sobre as pessoas sem a mediação das coisas e da matéria" (2001). Esta ideia, dirigida para o entendimento de pluralidade da condição humana, mostra que o mundo é habitado por pessoas que interagem entre si. Neste sentido, interação é um processo contínuo de ações que respondem a outras ações, com poder de afetar os outros (ARENDT, 2001). Por isso, Parsons entendeu a ação como um comportamento humano devidamente analisado e direcionado que resulta da relação entre a perceção de um problema e a motivação para o resolver (PARSONS; SHILS, 2007), acrescentando que:

Each orientation of action in turn involves a set of objects of orientation. These are objects which are relevant in the situation because they afford alternative possibilities and impose limitations on the modes of gratifying the needs and achieving the goals of the actor or actors (PARSONS; SHILS, 2007, p. 4).

Neste contexto, a ideia de ação associa-se à construção da transformação social a partir da sua dimensão de historicidade (GUerRA, 2006), uma vez que a ação, "na medida em que se empenha a fundar e a preservar corpos políticos, cria a condição para a lembrança, ou seja, para a história" (ARENDT, 2001).

A ação coletiva emerge dos moldes da ação, distinguindo-se, conforme afirma Erik Neveu, por ser "uma acção comum tendo como objectivo atingir fins partilhados" (in GUERRA, 2006, p. 57) e que, segundo a tradição de Chicago, se dá pela ação de um acontecimento desencadeador (p. 62). Embora envolta num campo de diversificadas interpretações, a ação coletiva foi sendo observada, a partir da sociologia do comportamento coletivo, de forma demasiado simplificada (MELUCCI, 1996), levando a que tenham sido integradas numa única categoria de análise uma multiplicidade de fenómenos coletivos, desde ações espontaneamente provocadas às revoluções planeadas (MELUCCI, 1996); ou manifestações de contestação geradas por movimentos sociais e outras ações de menor dimensão organizativa ou política (GARRETÓN, 2002).

Na tentativa de definir uma ação como ação coletiva, Melucci propõe uma designação que toma a ação coletiva como um conjunto de práticas sociais que envolvem e comprometem um conjunto de indivíduos ou de grupos, que exibem características morfológicas semelhantes em contiguidade de tempo e de espaço, que comportam um campo de relações sociais e uma capacidade de as pessoas envolvidas atribuírem um sentido à sua ação conjunta (MELUCCI, 1996; GUERRA, 2006).

Diversos conceitos de desenvolvimento estão intimamente ligados à existência de processos coletivos e participativos, através dos quais os sujeitos se envolvem na análise e na resolução dos problemas que os afetam directamente (LAMmerink; BurY; Bolt, 1999; SAntos, 2001; PereiRA, 2012), criando condições para a tomada de decisão sobre os mesmos. Estes processos, em si, impelidos por grupos de protesto como a Plataforma do Choupal, encontram-se estreitamente vinculados à geração de inclusão social, igualdade e justiça (CHINCHILA, 2006; VAN ZOMERAN; IYER, 2009). Pensar em participação 
é pensar no sujeito enquanto elemento primordial da mudança social, e enquanto produtor de historicidade.

Alain Touraine, na obra $O$ retorno do actor, evidencia o conceito de sujeito enquanto potencial representativo da "capacidade dos homens de se libertarem tanto dos princípios transcendentes como das regras comunitárias" (TOURAINE, 1996, p. 66). O sujeito é igualmente identificado com a ideia de consciência e de capacidade criadora, situando.o na base de uma sucessão de transformações sociais sobre as quais poderá agir e tornar-se ator social. Ou, como refere Isabel Guerra invocando o pensamento de Touraine, o ator é "um elemento produtor da sociedade" (GUERRA, 2006, p. 20). Neste sentido, interessa reter que, definido o sujeito pela sua criatividade, "pode admitir-se a ideia de um conflito social central, e a ideia de ação orientada para valores" (TOURAINE, 1996, p. 71) que regem a ação dos sujeitos e sobre os quais se dá o conflito presente na base do estudo de que este artigo trata: o conflito entre o valor de defesa de um espaço de natureza e lazer, considerado um bem público a manter, e o valor de uma travessia rodoviária benéfica para a política e a economia nacional.

A ação coletiva é, efetivamente, um campo de conflitos e os contributos teóricos provenientes do seu estudo revelam divergências muito significativas que, ao longo do tempo, se vêm considerando complementares. Por um lado, encontram-se as abordagens racionalistas que apontam a ação coletiva como o resultado de um conjunto de interesses e, por outro, a visão de que outros fatores, como as emoções, influenciam a organização de grupos de contestação e de ação social.

Até à década de 1960, o surgimento da ação coletiva era associado a um conjunto de emoções características do comportamento coletivo. Tais emoções eram associadas a comportamentos imaturos gerados pela impressionabilidade, raiva e violência dos indivíduos quando reunidos em grupos ou multidões (Goodwin; JASPER; PoletTA, 2004, p. 414-415). Perante esta vulnerável credibilidade das emoções, a abordagem racionalista foi ganhando espaço, trazendo contributos de maior rigor científico ao debate teórico em torno da ação coletiva, mostrando que este comportamento coletivo tem por base uma racionalidade, fundada na noção de utilidade. Conforme esclarece Alcides A. Monteiro, os autores próximos da teoria da escolha racional, em que se incluem Mancur Olson e Charles Tilly, advogam que "a ação coletiva explica-se pela utilidade que daí decorre para os seus membros" (MONTEIRO, 2004a, p. 119), assim como se organiza "em torno da utilidade que revela para os seus membros" (p. 119). A ideia de valor, acima associado ao caso do Choupal, com base nas ideias de Touraine e Parsons, encontra-se aqui como pedra angular. Este sentido de atribuição de um valor à ação em causa leva a observar a ideia que desvenda Olson de que "os indivíduos em grupo agem de acordo com os seus interesses pessoais" (OLSON, 1998, p. 1), conferindo à ação coletiva a dimensão utilitarista que a tem qualificado tradicionalmente, desde os anos 1960. Em complemento, Charles Tilly introduz a questão da dimensão política da mobilização, associando esta utilidade ao tempo que cada sujeito tem disponível para participar em ações do seu interesse. Tilly centra a sua análise na evolução do caráter da ação coletiva, defendendo que as formas de ação se substituem ao longo da história e que a escolha de um certo tipo de ação responde a considerações estratégicas por parte dos atores. 0 objetivo das mobilizações ofensivas, com que se identifica a ação coletiva dos séculos XIX e XX e que substituíram as ações de pendor mais reativo e defensivo características dos séculos XVII e XVIII, é essencialmente político e passa por obter uma maior participação nas instâncias de poder e influência (TILLY, 1986). 
MONTEIRO, A. A.; MONTEZ, M. M. Sentidos de mobilização e de desmobilização...

As teorias normativas e da escolha racional, entre as quais se contam os citados contributos de Mancur Olson, sob a égide da economia, mas também da teoria da privação relativa ou da teoria da identidade social, assim como a visão política de Charles Tilly, continuam a dominar a análise sobre a ação e a participação coletivas. Mas, se por um lado as abordagens racionalistas trouxeram contributos de cientificidade, por outro lado ignoraram a importância das emoções no processo de formação da ação coletiva. Por isso, de forma distinta, outras análises têm vindo a dar igual ênfase às variáveis emocionais envoltas no quadro de motivações que conduzem os indivíduos à participação em manifestações coletivas (FLAM, 1990; JASPER, 1998; VAN ZOMERAN; IYer, 2009; DRURY; ReICHER, 2009; SABUCEDO et al., 2010), o que, por sua vez, não deve ser interpretado como o reconhecimento de uma irracionalidade inerente a essas motivações, uma vez que as emoções na ação coletiva resultam de um processo cognitivo de entendimento do grau de proximidade de uma ameaça (JASPER, 1998). Para além de serem culturalmente construídas e muitas vezes ligadas a valores morais impregnados de direitos e obrigações, as emoções serão mais consistentes, constantes e previsíveis do que se poderia imaginar (THOITS, 1989; JASPER, 1998; 2011). Pelo que, a par das visões normativa e racional, a consideração da dimensão emocional (MENDONÇA, 2011) constitui-se como um importante contributo para uma mais completa compreensão da ação coletiva (FLAM, 1990), atuando igualmente como preditor da sua eclosão, desenvolvimento, possível interrupção e desmobilização.

Nos últimos anos os estudos sobre os movimentos sociais e a ação coletiva têm-se distanciado da abordagem racionalista (ESTANQUE, 1999), tendo vindo a debruçar-se com maior atenção sobre a dimensão subjetiva associada à participação dos indivíduos em manifestações coletivas (JASPER, 2011). A ação coletiva tem sido então observada de uma perspetiva política e cultural, para além da económica, associando-se-Ihe uma dimensão emocional. De acordo com esta perspetiva, a ação de cada sujeito num coletivo despoleta-se a partir de um conjunto de emoções resultantes da compreensão de uma ameaça (pelo que não se poderão considerar não racionais) e comportam formas tão diversas como o afeto, a identidade, a moral, a raiva, o medo, a injustiça e a indignação (JASPER, 1998; 2011). Nesta abordagem salientam-se ainda elementos tais como a importância do compromisso, do altruísmo e das razões ideológicas, que moldam a identidade política da ação coletiva, contrapondo ou complementando o fator interesse relevado pela abordagem económica (QUIRós, 2009) e, por conseguinte, conferindo à ação coletiva um caráter mais completo.

O estudo das emoções na ação coletiva e na geração de movimentos sociais tem produzido conhecimento sobre as emoções, levando ao reconhecimento da existência de um complexo processo cognitivo e físico nas emoções. Neste âmbito, Jasper organiza, apresenta e explora várias categorias de emoções, que denomina de Dimensões Emocionais dos movimentos sociais (GoOdWIN; JASPER; POLETTA, 2004). As categorias que Jasper apresenta são analisadas em consonância com casos reais de ação coletiva ou de outros comportamentos de idêntica natureza:

a) Emoções reflexas: O medo, surpresa, aversão/revolta, zanga, felicidade, e tristeza são processos muito complexos que contemplam processamento de informação e de sua avaliação, assim como alterações físicas que incluem as expressões faciais e que se dão no mesmo sentido que os reflexos musculares. 
b) Emoções afetivas: Amor, ódio, respeito e confiança são emoções que persistem durante um longo período de tempo, proporcionam a orientação de base de um sujeito para uma ação e conduzem ao compromisso e investimento positivo ou negativo em relação a pessoas, lugares, ideias e objetos.

c) Humor: São emoções relacionadas com alterações bioquímicas, transportáveis de uma situação para outra, afetando cada nova situação conforme o humor que se transporta. O otimismo é uma das emoções resultantes desta dimensão de emoções e afeta seriamente o sucesso das ações coletivas.

d) Emoções morais: Refletem a compreensão que cada sujeito tem do mundo ou dos contextos à sua volta e influenciam diretamente a participação de um sujeito numa ação. Nesta dimensão encontram-se emoções como compaixão, indignação e choque moral.

e) Estratégia: Revolta e aversão são emoções sentidas em relação a situações concretas e motivam a ação. Estas emoções têm sido estrategicamente utilizadas ou apropriadas para gerar contestação, sentimento de grupo e ação contra o que os líderes dos grupos de protestos e de ações coletivas consideram ser ameaças às causas e ideias que defendem.

O caso da Plataforma do Choupal, aqui apresentado, revelou-se um exemplo da importância das emoções na ação coletiva pela forma como aspetos referidos nestas dimensões (afeto, culpa, raiva, indignação, e outras) condicionaram a mobilização e também a desmobilização da ação.

\section{Contextos de um conflito na base da ação coletiva}

O conflito é um elemento constante em toda a ação coletiva, fundamental nos processos políticos e portador de uma tensão necessária entre movimentos sociais e democracia (PEREIRA, 2012). No presente caso, o conflito dá-se pela divergência de visão dos atores implicados, no que concerne a modelos de desenvolvimento e de democracia, num contexto territorial e numa conjuntura histórica e política que são particulares. A conjuntura em causa é o início da crise económica e social que marca drasticamente, na atualidade, Portugal e outros países europeus desde 2009. No entanto, o tempo desta ação coletiva abrange ainda a fronteira final de uma época dedicada à promoção do "local" (dos atores locais e das iniciativas locais) enquanto espaço de resolução de problemas sociais complexos, em contraponto à evolução da globalização (FERREIRA, 2004). Por sua vez, à semelhança de outros conflitos sociais que "decorrem sob o ritmo da reestruturação espacial" (ESTANQUE, 1999, p. 93), a origem da ação social reporta-se a um contexto territorial e espacial, que importa também conhecer.

Partindo de uma perspetiva macro-micro, refira-se que o território no qual surge a ação coletiva da Plataforma do Choupal é a cidade de Coimbra, estendendo-se pontualmente para outros territórios, como Lisboa, por ser a capital do país, em ações pontuais. A cidade de Coimbra situa-se no centro de Portugal, e é ponto de passagem na ligação rodoviária entre as cidades de Lisboa (a $200 \mathrm{~km}$ ) e Porto (a $100 \mathrm{~km}$ ). Com uma área urbana de $3.000 \mathrm{ha}^{3}$, tem sido considerada a terceira maior cidade do país, com 143.396 habitantes a nível do município4. A cidade é limitada a sul pelo rio Mondego que corre no

\footnotetext{
${ }^{3}$ Fonte: página da Internet da Sociedade de Reabilitação Urbana - Coimbra Viva, em: <http://www.coimbravivasru.pt/coimbraviva.php>, visitada em 29 de maio de 2012.

${ }^{4}$ A cidade de Coimbra conta com 106.800 habitantes. Fonte: página da Internet de Sensos 2011 - Resultados Provisórios, em: <http://www.ine.pt/scripts/flex_provisorios/Main.html>, visitada em 29 de maio de 2012
} 
MONTEIRO, A. A.; MONTEZ, M. M. Sentidos de mobilização e de desmobilização...

sentido nascente-poente. É no seguimento deste mesmo rio, para poente da cidade, que se encontra o território que motivou a ação coletiva da Plataforma do Choupal: precisamente, a Mata Nacional do Choupal.

Esta Mata situa-se aproximadamente $1,5 \mathrm{~km}$ a poente do centro da cidade. Trata-se de um espaço de cerca de 71 hectares de Reserva Ecológica Nacional submetido ao Regime Florestal Total ${ }^{5}$ mas sem o estatuto de área protegida. Popularmente denominada de Choupal, a mata foi plantada no final do século XVIII na margem norte do rio Mondego. Das várias espécies plantadas, sobressaiu o choupo negro, originando o nome pelo qual é conhecida. Amputada a partir dos anos 1970 em cerca de 25\% da sua área, devido a obras públicas de variada natureza, em 2010 enfrentou uma nova ameaça: um novo traçado da via rodoviária IC2 (Itinerário Complementar 2) que liga as cidades de Lisboa e Porto numa variante ou em sobreposição à Estrada Nacional 1 . Em Coimbra, a revisão do seu traçado contempla uma nova travessia do rio Mondego, alguns metros a poente da atual ponte-açude, que atravessa a Mata Nacional do Choupal por meio de um viaduto de 40 metros de largura, com perfil de autoestrada.

Como previsto na lei portuguesa relativa a matéria de obras públicas, e tratando-se de uma obra sobre um espaço que contempla ecossistemas naturais, foram solicitados pelo Estado pareceres técnicos sobre o projeto de atravessamento do Choupal, cujas conclusões foram desfavoráveis à construção do viaduto. Contudo, não sendo estes pareceres vinculativos à decisão política, o Ministério do Ambiente emitiu em 2008 a primeira Declaração de Impacto Ambiental (DIA) favorável ao projeto. A decisão política de construção de um viaduto rodoviário sobre o Choupal teve o apoio da autarquia de Coimbra, que viu neste projeto uma forma de requalificar parte da zona urbana periférica ao Choupal. Foi também acolhida com agrado por grupos de pessoas que consideram as obras deste género como um sinal de progresso. Mas, ao mesmo tempo, deu origem a uma dinâmica de contestação organizada sob a forma de movimento cívico, denominado Plataforma do Choupal.

\section{Problemas de partida da ação coletiva da Plataforma do Choupal}

A decisão política de resolução de um problema de trânsito rodoviário de nível nacional, marcado pela necessidade de aproximação espacial e temporal entre duas grandes cidades - Lisboa e Porto -, gerou três novas dimensões de problemas:

a) um problema ambiental;

b) um problema sociocultural;

c) um problema político e de cidadania.

O problema ambiental relaciona-se com a colocação em perigo de um conjunto de ecossistemas que caracterizam o Choupal, devido ao leque de tipologias de poluição resultantes da travessia rodoviária e da obra de construção. Impossibilita também a utilização deste espaço como lugar de educação ambiental, tornando-se, por conseguinte, num exemplo contrário.

\footnotetext{
${ }^{5}$ Decreto-Lei 254/2009 de 24 de setembro que aprova o Código Florestal.
} 
O problema sociocultural manifesta-se pelo condicionamento ou privação de práticas de lazer e de convívio social que acontecem no Choupal. A médio-longo curso coloca-se também em risco a mobilidade e a qualidade de vida na cidade, uma vez que se prevê que o novo percurso da IC2 afetará o trânsito rodoviário, levando a uma maior utilização das vias de acesso ao centro, pondo em causa a lógica de desenvolvimento sustentável da cidade. Com uma nova amputação o Choupal afastar-se-á da cidade. No campo simbólico o projeto põe em risco o valor patrimonial do Choupal enquanto espaço histórico preservado pelo imaginário coletivo da cidade de Coimbra.

O problema político e de cidadania é resultado da falta de transparência na tomada de decisões políticas e consequente desacreditação das formas de governança de nível local e nacional. Num quadro político de democracia surge, da parte dos cidadãos, a expetativa de participação na tomada de decisões que Ihes dizem respeito e os mesmos "já não admitem que os processos de planeamento e de gestão urbanística sejam elaborados por um grupo de decisores e técnicos em ambiente de obscurantismo" (GUERRA, 2000, p. 38).

As três dimensões de problemas e seus conteúdos reproduzem-se igualmente como quadros de motivação pessoal e de perceção dos riscos, que conduziram os sujeitos ao processo da ação coletiva em causa.

\section{Opções metodológicas}

A análise que aqui se documenta resultou de um estudo de caso e assentou em metodologias de pesquisa indutiva. Centrou-se, sobretudo, na análise de conteúdo de entrevistas a elementos do movimento cívico, complementada com a análise de documentos referentes às ações do movimento, de artigos de jornais, de reportagens de televisão, e ainda de sítios da internet. Acessoriamente, foram estabelecidos contactos e obtidos testemunhos por parte das lideranças de um movimento cívico espanhol - Salvem El Cabanyal ${ }^{6}$-, uma vez que os documentos e estudos disponíveis apontavam para fortes afinidades entre este e a Plataforma do Choupal.

Os elementos da Plataforma do Choupal entrevistados foram fundadores do movimento, participantes desde o início do processo, e integrantes do movimento em fases posteriores ${ }^{7}$. A fase de pesquisa aconteceu num tempo em que o movimento cívico desanimou, tornando-se volátil na sua intervenção e mais difícil a relação entre esta pesquisa e a ação concreta do movimento. No entanto, tal fator também favoreceu um relativo distanciamento dos sujeitos perante as suas ações, resultados e sentimentos, possibilitando-Ihes uma leitura mais crítica dos acontecimentos e dos percursos.

A metodologia de análise das entrevistas feitas aos protagonistas da ação coletiva segue de perto a proposta elaborada por Demazière e Dubar, a de uma "postura analítica que procura produzir

\footnotetext{
${ }^{6}$ O movimento Salvem El Cabanyal é um movimento cívico criado na cidade de Valência em 1998, e existente atualmente, em defesa da demolição dos bairros El Cabanyal e Canyamelar para ampliação da avenida Blasco Ibañez até ao mar Mediterrâneo, de acordo com um projeto urbanístico municipal iniciado no final do século XIX. Ver: <www.cabanyal.com>.

7 Entrevistados/as: Luís S., arquiteto, ativista em Coimbra, fundador do movimento. Entrevistas exploratórias 1 e 2 e semiestruturada 1. Miguel D., professor, elemento do Bloco de Esquerda, fundador do movimento. Entrevista semiestruturada 2. José P., reformado, participante. Entrevista semiestruturada 3. Teresa S., jurista, participante. Entrevista semiestruturada 4. Emílio M., arquiteto e professor universitário, fundador do movimento Salvem El Cabanyal. Entrevista estruturada.
} 
MONTEIRO, A. A.; MONTEZ, M. M. Sentidos de mobilização e de desmobilização...

metodicamente um sentido a partir da exploração de entrevistas de pesquisa" (1997, p. 34). Os autores estruturaram uma abordagem dos discursos dos sujeitos (orais ou escritos) com fortes afinidades à Grounded Theory desenvolvida por B. Glaser e A. Strauss, visando à construção de teoria a partir de uma análise intensiva de casos e marcada por uma constante comparação entre dados empíricos. Definem o processo indutivo de teorização como organizado em três operações principais. Uma primeira operação, de tradução/nominação, em que os dados coletados são traduzidos em momentos e categorias analíticas, necessariamente provisórios. A operação seguinte permite o afastamento em relação aos dados originais (matéria-prima) e um trabalho de estruturação das categorias num sistema mais coerente e mais integrado de hipóteses. A última operação conduzirá, por processos de conceptualização e abstração, à formulação de proposições teóricas dotadas de coerência lógica. Através da análise comparativa de discursos e sua categorização, avança-se dos discursos individuais e subjetivos em direção a categorias mais formais e abstratas que conferem sentido ao "objeto sociológico" sobre o qual a pesquisa se debruça.

Contudo, esta abordagem mais naturalista e indutiva que recai sobre os referentes - as relações sociais, normas e processos de ação social mediatizados pelo discurso de atores que neles intervêm ativamente - não inviabiliza o recurso a um quadro teórico em apoio, do mesmo modo que esse recurso pode não comprometer o raciocínio indutivo (é o que se deseja). O uso de um quadro teórico de referência surge como via para ir mais além da nebulosa de significações pessoais, para conhecer o alcance das suas conceções acerca de si próprios e do seu lugar no mundo, identificar a totalidade social da qual cada indivíduo e cada situação fazem parte, bem como refinar interpretações para além dos significados mais imediatos (ALVESSON; SKÖLDBERG, 2000; MONTEIRO, 2004a).

Génese de uma ação coletiva: das emoções às perceções de risco e de ameaça

No caso da Plataforma do Choupal, residem diversas motivações para a ação coletiva. 0 enfoque dado neste artigo recai sobre as motivações que se consideram de ordem emocional, levando em conta que as emoções se complementam ou se articulam com o caráter racional da ação coletiva. Esta complementaridade não só é geradora de conflito como de uma mais abrangente complexidade no entendimento da ação coletiva.

As motivações observadas no caso da Plataforma do Choupal prendem-se, num primeiro olhar, com perceções individuais de risco em relação à implicação do viaduto rodoviário sob os bens (lugar/espaço) de que os sujeitos são usufruidores. Por isso esboçar algumas considerações sobre o conceito de risco. Segundo o conhecimento produzido pelas ciências do risco, nas palavras do geógrafo Fernando Rebelo, a noção de risco está associada aos conhecimentos das variáveis que comportam a possibilidade de perigo e de crise e sua proximidade (ReBeLo, 2003; 2010). O risco é o somatório "de algo que nada tem a ver com a vontade do homem ("aleatório", "acaso", "casualidade" ou "perigosidade"), com algo que resulta, direta ou indiretamente, da presença do homem, a vulnerabilidade" (REBelo, 2003, p. 259). Numa abordagem antropocêntrica, o conceito de vulnerabilidade implica a presença humana e não se considera haver risco quando a ação não implica 
com a humanidade ou com os seus bens. Todavia, numa visão holística, qualquer risco, por mais distante que se encontre da presença humana, afetará sempre a humanidade (REBELO, 2003, p. 252).

Mercedes Pardo aponta alguns aspetos que suportam o entendimento sobre as perceções de risco descritas neste artigo. Em primeiro lugar, a ideia de que risco está dependente da própria consciência grupal e social de risco (PARDO, 2002), pautando a ação dos sujeitos perante acontecimentos que implicam com os espaços, com as pessoas e com os seus recursos. Em segundo plano, a perceção de risco é relativa e diferenciada, uma vez que não afeta de igual forma todos os indivíduos nem todos os setores da sociedade (BeCK, 1992; BeCK; GIdDEns; LASH, 2000; PARDo, 2002). Neste sentido, Pardo aponta a forma comum de relação social com o risco, geralmente promovida pelas instâncias que detêm o poder: a opção de remeter o risco para outros lugares da sociedade onde há mais controle social ou onde a consciência do risco não gere conflitos. Desta forma, a potencial ação coletiva advinda da perceção do risco não se torna tão possível. Um terceiro aspeto é o facto de que as sociedades comportam, elas próprias, uma capacidade de produção da perceção do risco, normalizando o que é perigoso e o que não é perigoso (PARDo, 2002). No caso da problemática em torno do Choupal, este fenómeno é evidente, uma vez que a ideia de que não há risco na travessia do Choupal por um viaduto rodoviário é ainda generalizada, quer pelo poder autárquico, quer por um grande número de habitantes da cidade, quer pelo próprio órgão do governo que deliberou sobre o reduzido risco desta travessia pela mata.

Considerado o caráter de relatividade do risco, sua necessidade de consciencialização social e remissão para os "outros lugares" referidos por Pardo, vislumbra-se uma possível interpretação relacionada com o problema em estudo: territórios com nenhuma ou reduzida ocupação humana estão sujeitos a ações de transformação artificial, sem que sejam considerados os riscos tecnológicos a que estão expostos ${ }^{8}$. Porém, as perceções que cada grupo social desenvolve em torno dos riscos inerentes a uma ameaça conferem ao risco um papel preponderante na evolução das sociedades e da humanidade pois, "sans risque, il ne se produirait aucune activité et, à l'évidence, il n'y aurait pas d'innovation sociale" (PARDO, 2002, p. 2). Tira-se daqui a ilação de que o risco é, portanto, gerador de ação.

No caso em estudo, as perceções de risco que motivaram a ação coletiva resultam da notícia de construção do viaduto e podem-se organizar em três quadros de perceção de risco e de motivação, coincidentes com os problemas já anteriormente mencionados: a) de ordem ambiental; b) de ordem sociocultural; c) de ordem política e de cidadania.

As perceções de risco aliam-se diretamente a um quadro de emoções proveniente do afeto sentido pelos sujeitos em relação ao espaço da Mata do Choupal e à cidade de Coimbra. Sem este sentimento de afeto, e consequentes emoções geradas pela iniciativa de construção do viaduto, não se revelariam perceções de risco. Por outro lado, emergem, mesmo que intangíveis, emoções de ordem moral e reflexas. Tendo em conta o sentido e a importância apontados às emoções, considera-se que o sentimento de risco em relação à Mata do Choupal advém então da relação emocional entre os sujeitos e o lugar em causa, conduzindo a motivações concretas para a ação. O quadro de motivações para a ação

\footnotetext{
8 Por riscos tecnológicos entendem-se os riscos provenientes da ação humana, as produções industriais, o trânsito, os transportes (REBELO, 2003).
} 
MONTEIRO, A. A.; MONTEZ, M. M. Sentidos de mobilização e de desmobilização...

coletiva é assim preenchido por uma palete diversificada de perceções, de interesses pessoais, de processos cognitivos, de valores e de emoções que cada sujeito tem ou sente perante os bens que usufrui ou em relação aos espaços que valoriza, tornando possível identificar a existência de uma ameaça concreta ao bem-estar e às condições de vida desejadas por este grupo de pessoas. As motivações pessoais e as perceções de risco relacionam-se com as experiências, interesses, ideologias e relações dos sujeitos, nomeadamente neste caso, com: o Choupal; a cidade de Coimbra; um paradigma de desenvolvimento integrado que comporta expetativas de cidadania próprias. No entanto, interessa destacar que apesar da diversidade de motivações e da natureza individual das emoções e das perceções, a ameaça é, no entanto, objetiva, identificada e considerada de forma comum no grupo. Das entrevistas realizadas emerge um apontar geral da construção do viaduto sobre o Choupal como a ameaça e a razão da mobilização do movimento cívico com uma ação coletiva.

Em todos os testemunhos dos fundadores da Plataforma do Choupal recolhidos para o estudo de caso em que se baseia este artigo estão presentes emoções pessoais muito significativas para o despoletar da ação coletiva. Releva-se, pelas vozes dos atores, uma multiplicidade de emoções relativas à sua ação no movimento cívico. Emoções como o afeto, a indignação, o choque moral e o medo estiveram na origem da criação do movimento, por uns, e da agregação ao movimento, por outros. Ao mesmo tempo observam-se emoções relativas ao sentimento de justiça ou de injustiça em relação às decisões políticas de transformação daquele lugar e de gestão da cidade e emoções de felicidade e de tristeza relativas aos sucessos e insucessos do movimento.

$\mathrm{O}$ afeto que os fundadores do movimento sentem pelo espaço da Mata do Choupal é de tal ordem importante que chegam a projetar para aquele espaço uma personalidade humana expressa pelo recorrente termo "amputação", quando se referem à construção do viaduto e a outras obras públicas anteriores que reduziram o espaço da Mata. Observa-se também um conjunto de afetos vinculados a memórias de infância e à memória histórica e cultural do Choupal e da cidade de Coimbra.

As vozes dos atores, em entrevistas realizadas, transmitem o leque de emoções, de motivações e de perceções de risco, emersos na sua complexidade, a que interessa tomar atenção.

\footnotetext{
Foi essa a motivação. Uma predisposição já para questões ambientais. Ali na questão do Choupal, uma em particular é que eu era utente do Choupal e senti-me pessoalmente atacado, agredido, com um projeto daqueles (entrevista a Miguel D.).

Chego à Plataforma do Choupal muito mais por questões de ordem urbana, que têm a ver claramente com o centro histórico, do que propriamente com o atentado evidente que existe relativamente à Mata do Choupal (entrevista a Luís S.).

Chegamos a ter motivações claramente de visibilidades, protagonismos bacocos, coisas dessas. Chegamos a ter participações desse tipo (entrevista a Luís S.).

[...] Havia pessoas apenas que achavam que aquele pedaço da sua cidade era de todos nós, havia pessoas que apenas achavam demasiado o dinheiro, de tudo. As motivações eram diversas, embora pense que toda a gente tivesse algum... acho que toda a gente tinha, por um lado, a preocupação com a sua cidade, porque eram pessoas daqui que queriam viver melhor, isso sim era transversal, e com algum prazer pela natureza, por um pouco de verde (entrevista a Teresa S.).
}

A Declaração de Impacto Ambiental emitida pelo governo em 2008, que aprovou o projeto de travessia do Choupal por uma via rodoviária em forma de viaduto, tornou-se o acontecimento 
desencadeador da ação coletiva. Considerando os fatores de mobilização enunciados por Melucci, este acontecimento foi essencial para a mobilização dos sujeitos, por ser identificado como adversário em conflito com os valores, recursos e ideologias que eles consideram em risco (MELUCCI, 1996). A partir do momento da primeira mobilização inicia-se um percurso evolutivo até à ação coletiva propriamente dita, no qual a performance da ação coletiva depende da relação de proximidade da ameaça aos bens que os sujeitos usufruem. Os afetos sentidos pelo espaço do Choupal, pela cidade de Coimbra e, entre elementos do grupo, nomeadamente por aqueles que demonstraram iniciativa e liderança. A culpa, a raiva e a indignação surgiram como reação à identificação de uma ameaça tecnológica sobre os espaços prezados e os valores das pessoas do grupo e tornou-se mais ou menos significativa quanto maior ou menor foi o sentimento de proximidade de uma ameaça ao Choupal e aos valores culturais e políticos dos elementos do movimento. A ação da Plataforma do Choupal, entre 2008 e 2010, ilustra muito significativamente a compreensão deste fenómeno.

\section{Percurso de uma ação coletiva: da ação à desmobilização}

Conforme testemunhos dos fundadores da Plataforma do Choupal, o movimento, enquanto grupo de sujeitos propriamente dito, foi originado pela associação de pessoas sensíveis às notícias publicadas no blog SOS Choupal, entre 29 de outubro e 11 de novembro de 2008. Constitui-se maioritariamente por homens e mulheres com anteriores participações na política local da cidade de Coimbra, quer como cidadãos independentes impelidos por um sentido apurado do exercício da cidadania, quer como militantes de partidos políticos, nomeadamente do Bloco de Esquerda:

Acho que há um momento inicial, que é um blog [...] que traz uma notícia bombástica que está planeada a travessia do Choupal por um viaduto. Era o SOS. Cada um por si tomou conhecimento da existência de um projecto desse género (entrev. A Miguel D.).

Após o conhecimento do blog, alguns sujeitos com anteriores participações cívicas no concelho de Coimbra e frequentadores da Mata do Choupal conversaram entre si e decidiram tomar ação (entrev. a Miguel D.).

E dentro desse partido político [a que pertence] eu coordenava a área ambiental e na altura fiz qualquer coisa dentro do meu partido para alertar para aquela questão. Mas a coisa não flui por aí. Posteriormente, o que é que acontece? Eu era utente do Choupal. [...] E um dia deparo-me lá com uma equipa de jornalistas. Eles estavam a entrevistar pessoas e eu parei e praticamente ofereci-me para ser entrevistado. Na altura anunciei uma coisa que não existia: que haveria aí um grupo de pessoas que iria começar uma luta. E a partir daí senti. me comprometido e entrei em contacto com várias pessoas [...]. E dá-se uma primeira reunião entre aquilo que depois viria a ser um pouco o núcleo duro da plataforma do Choupal (entrev. a Miguel D.).

Surge uma notícia num jornal local dizendo que havia um blog que abordava a questão do iminente lançamento de uma empreitada sobre o Choupal. Consultando esse blog, percebi um bocadinho melhor o que estava em causa, e precisamente vindo de uma reflexão feita 
MONTEIRO, A. A.; MONTEZ, M. M. Sentidos de mobilização e de desmobilização...

no concelho da cidade sobre questões absolutamente decisivas que se passam neste momento com o centro da cidade de Coimbra e da sua relação com rio [...]. A minha questão é esta: enquanto que a reação da generalidade das pessoas que chega, mesmo à organização do movimento, tem a ver com o grave atentado sobre a Mata Nacional do Choupal, há outras, como eu, em que a razão pela qual chego tem a ver com aquilo que se passa no centro histórico de Coimbra, nas questões que têm a ver com mobilidade e com o entendimento que eu tenho de um fortíssimo potencial da cidade (entrev. a Luís S.).

Ouvi falar sobre o que estava projetado e sobre a iniciativa de algumas pessoas que queriam combater isso. Achei que valia a pena e fui [...]. E nessa sessão pública, mesmo no próprio Choupal, falou-se em reuniões [...]. Eram abertas a toda a gente, e assim foi. Fui uma noite, quem estava na reunião eram pessoas muito diferentes umas das outras, de formação, de cursos, de filiação política, sei lá. E além disso foi muito acessível, foi fácil chegar, mesmo não tendo nenhuma participação ativa anterior, ou nenhuma experiência, digamos, os nossos contributos foram aceites com facilidade, como se fizéssemos parte há muito tempo (entrev. a Teresa S.).

$\mathrm{E}$, numa dessas minhas idas ao Choupal, fui confrontado com muita gente, junto àquela pontezita [...]. Parei a bicicleta, fui ver o que era [...] eu vim a saber que se tratava de um movimento que pretendia impedir ou dificultar, ou arranjar alternativas para o viaduto que estavam a pretender construir, não é? E pronto, na altura lembro-me que assinei um papel, portanto constituí-me imediatamente como um dos subscritores da providência cautelar [...]. E pronto, e passei a envolver-me com a Plataforma do Choupal nas iniciativas que foram decorrendo... (entrev. a José P.).

No início de dezembro de 2008 , os sujeitos realizaram a primeira reunião com cerca de sete participantes. Nesse momento definiram-se como estratégias: a) obter informação sobre o assunto; b) avançar com uma subscrição pública; c) realizar um conjunto de ações de animação que captassem a atenção para o que consideravam ser o problema em causa.

Nós delineámos uma pequena estratégia que passou, precisamente, pela obtenção da informação mais detalhada sobre a questão e passou pela decisão de se avançar com uma qualquer subscrição [...] e de imediato surgiu a ideia de um "abraço" também, a ideia de abraçar o Choupal, que se realizou aí em inícios de fevereiro [de 2009] (entrev.a Luís S.).

Depois foi criado um sítio na Internet (atualmente desativado) para informação das atividades do movimento e do problema. Em fevereiro de 2009 formou-se o grupo que se manteve mais participativo, constituído por 12 a 20 pessoas com participação frequente nas reuniões. Até ao final de 2010 tinham sido realizadas 38 reuniões. Para promoção da causa, e da Mata do Choupal, o movimento definiu a realização de atividades que mobilizassem a população de Coimbra, e chamassem a atenção dos meios de comunicação social, e da sociedade portuguesa. Interessava fazer compreender o Choupal enquanto espaço a preservar na cidade e alertar para a ameaça de que consideravam estar a ser alvo. Foi então definido um conjunto de atividades para as quais mobilizaram outras organizações e sujeitos, entre os quais artistas e personalidades conhecidas da sociedade portuguesa. $O$ historial da ação 
coletiva da Plataforma do Choupal contemplou atividades de grande mobilização de pessoas, entre dezembro de 2008 e a primavera de 2009, que se podem observar nos Quadros 1 e 2. Dessas destacam. se as seguintes:

a) petição para a Assembleia da República, com 11 mil assinaturas;

b) concerto em defesa do Choupal, no qual participaram artistas conceituados;

c) "abraço" ou "cordão" em volta da mata, onde participaram cerca de 1.300 pessoas;

d) 48 horas de atividade física no Choupal, que mobilizou diversos clubes e associações desportivas e atletas.

Quadro 1

Atividades pontuais realizadas pelo movimento cívico Plataforma do Choupal

\begin{tabular}{|c|c|c|c|c|c|}
\hline Atividade & Data & Descrição & Local & Organizações parceiras & $\begin{array}{l}\mathrm{N}^{\circ} \text { de } \\
\text { Participantes }\end{array}$ \\
\hline Petição pública & 2009 & $\begin{array}{c}\text { Petição contra a construção da IC2 e } \\
\text { contra a declaração de impacte } \\
\text { ambiental do secretário de Estado } \\
\text { do ambiente. }\end{array}$ & Internet & $\longrightarrow$ & 10.000 \\
\hline $\begin{array}{l}\text { "Cordão } \\
\text { humano pelo } \\
\text { Choupal" }\end{array}$ & $\begin{array}{l}15 \text { de } \\
\text { fevereiro } \\
2009\end{array}$ & $\begin{array}{l}\text { "Abraçar" o Choupal com pessoas } \\
\text { juntas. }\end{array}$ & $\begin{array}{l}\text { Mata Nacional } \\
\text { do Choupal }\end{array}$ & $\begin{array}{c}\text { ICNB; } \\
\text { Bar do Choupal; } \\
\text { ESECTV; } \\
\text { Escoteiros do Grupo } 222 \\
\text { de Escoteiros da Adémia. }\end{array}$ & 1.300 \\
\hline $\begin{array}{l}\text { "Primavera pelo } \\
\text { Choupal" }\end{array}$ & $\begin{array}{l}21 \mathrm{de} \\
\text { março } \\
2009\end{array}$ & $\begin{array}{l}\text { Espectáculo artístico com a } \\
\text { participação de: Manuel João Vieira; } \\
\text { JP Simões; Ena Pá 2000; Diabo a } \\
\text { Sete; Quarto Minguante. }\end{array}$ & $\begin{array}{l}\text { Teatro } \\
\text { Académico Gil } \\
\text { Vicente (TAGV) }\end{array}$ & $\begin{array}{l}\text { TAGV; } \\
\text { ESECTV; } \\
\text { Quarto Minguante; } \\
\text { Diabo a Sete. }\end{array}$ & Sem dados \\
\hline $\begin{array}{l}\text { "Limpeza do } \\
\text { Choupal" }\end{array}$ & $\begin{array}{l}10 \text { de } \\
\text { maio } \\
2009 \text { e } \\
20 \text { de } \\
\text { março de } \\
2010\end{array}$ & $\begin{array}{l}\text { Limpeza parcial da Mata do } \\
\text { Choupal. }\end{array}$ & $\begin{array}{l}\text { Mata Nacional } \\
\text { do Choupal }\end{array}$ & $\begin{array}{c}\text { ICNB; } \\
\text { CM Coimbra } \\
\text { Grupo } 222 \text { Escoteiros da } \\
\text { Adémia } \\
\text { Iniciativa Limpar Portugal }\end{array}$ & 50 \\
\hline $\begin{array}{l}\text { "Uma espécie } \\
\text { de corrida pelo } \\
\text { Choupal" }\end{array}$ & $\begin{array}{l}26,27 \\
28 \text { de } \\
\text { junho de } \\
2009\end{array}$ & $\begin{array}{l}48 \text { horas de prática desportivas, } \\
\text { sem interrupção. }\end{array}$ & $\begin{array}{l}\text { Mata Nacional } \\
\text { do Choupal }\end{array}$ & $\begin{array}{c}\text { ICNB; } \\
\text { Bar do Choupal; } \\
\text { Centro Hípico de Coimbra; } \\
\text { Clubes de Atletismo; } \\
\text { Clubes Desportivos. } \\
\end{array}$ & Sem dados \\
\hline $\begin{array}{l}\text { "Outono pelo } \\
\text { Choupal" }\end{array}$ & $\begin{array}{l}\text { Outubro } \\
\text { de } 2009\end{array}$ & $\begin{array}{c}\text { Ateliers de índole ambiental e } \\
\text { artística com crianças, dinamizadas } \\
\text { pelo pintor Mário Silva. }\end{array}$ & $\begin{array}{l}\text { Mata Nacional } \\
\text { do Choupal }\end{array}$ & $\begin{array}{c}\text { Associação } \\
\text { Ambientalidades. }\end{array}$ & Sem dados \\
\hline $\begin{array}{l}\text { Debate político } \\
\text { sobre Choupal }\end{array}$ & & $\begin{array}{c}\text { Debate entre candidatos à } \\
\text { autarquia, relativo ao Choupal e à } \\
\text { construção da IC2. }\end{array}$ & $\begin{array}{l}\text { Mata Nacional } \\
\text { do Choupal }\end{array}$ & - & Sem dados \\
\hline
\end{tabular}

Fonte: Elaboração própria com base nas entrevistas realizadas. 
MONTEIRO, A. A.; MONTEZ, M. M. Sentidos de mobilização e de desmobilização...

Quadro 2

Atividades frequentes e/ou contínuas realizadas pelo movimento cívico Plataforma do Choupal

\begin{tabular}{|c|c|c|c|c|c|}
\hline Atividade & Data & Descrição & Local & $\begin{array}{l}\text { Organizações } \\
\text { parceiras }\end{array}$ & $\begin{array}{c}\mathrm{N}^{\circ} \text { de } \\
\text { Participantes }\end{array}$ \\
\hline $\begin{array}{l}\text { Reuniões } \\
\text { semanais }\end{array}$ & $\begin{array}{c}\text { Até julho } \\
2009=28 \\
\text { Até fevereiro } \\
2010=38\end{array}$ & $\begin{array}{l}\text { Reuniões de discussão de } \\
\text { estratégias e propostas de } \\
\text { atividades. }\end{array}$ & $\begin{array}{l}\text { Galeria-Bar Santa } \\
\text { Clara; Café Santa } \\
\text { Cruz; Café Trianon; } \\
\text { Café Avenida }\end{array}$ & & $\begin{array}{l}\text { De } 8 \text { a } 20 . \\
\text { Com } \\
\text { frequência: de } \\
12 \text { a } 14 .\end{array}$ \\
\hline Ação judicial & $\begin{array}{l}\text { De } 2009 \text { até } \\
\text { à atualidade }\end{array}$ & $\begin{array}{c}\text { Ação judicial contra a DIA, } \\
\text { interposta por elementos } \\
\text { da Plataforma do Choupal } \\
\text { mas não formalmente pelo } \\
\text { movimento. }\end{array}$ & $\begin{array}{c}\text { Tribunal } \\
\text { Administrativo e } \\
\text { Fiscal de Coimbra }\end{array}$ & & 22 \\
\hline $\begin{array}{l}\text { Reuniões com } \\
\text { deputados e } \\
\text { grupos } \\
\text { parlamentares }\end{array}$ & $\begin{array}{c}\text { De } 2009 \text { a } \\
2010\end{array}$ & $\begin{array}{l}\text { Reunião com deputados e } \\
\text { grupos parlamentares de } \\
\text { vários partidos políticos } \\
\text { para sensibilização para o } \\
\text { problema do Choupal. }\end{array}$ & $\begin{array}{l}\text { Coimbra; } \\
\text { Assembleia da } \\
\text { República }\end{array}$ & - & Sem dados \\
\hline
\end{tabular}

Fonte: Elaboração própria com base nas entrevistas realizadas.

Ao longo do ano de 2009 o movimento realizou uma série de atividades nos campos jurídico, sociocultural e político. Mas, ao mesmo tempo, conjugaram-se acontecimentos pessoais, políticos e económicos que afetaram os dois lados do conflito, resultando na gradual desmobilização do movimento.

No plano económico: o brusco surgimento da atual crise, que condicionou politicamente a despesa pública em obras que ainda não estavam adjudicadas e consideradas não urgentes nem relevantes para o desenvolvimento nacional.

No plano político: deram-se mudanças no executivo da autarquia e do governo. Por um lado, segundo testemunhos dos atores, a autarquia manteve a sua postura de ignorar o movimento, apesar dos pedidos de reunião e manteve o entusiasmo na obra em questão. Por outro lado, foi anulado o concurso de adjudicação da obra, condicionado pelo orçamento público e por opções do governo nacional. Também se inscreve no plano político o conjunto de fatores com relevância no interior do movimento cívico. Com efeito, revelaram-se conflitos latentes, mas não assumidos, resultantes das diferentes perceções de risco, motivações e orientações, para a ação. Surgiram também problemas relativos à forma de liderança assumida pelo movimento, que se pretendia democrática e aberta à participação de todos os elementos, mas que resultou num conflito mudo entre potenciais líderes ou entre elementos com visões distintas sobre a orientação para a ação do movimento. Tal comportamento organizacional condiz com características das iniciativas consideradas de orientação militante e condicionou a participação efetiva dos elementos do grupo. Consequentemente, a evolução do grupo, em coerência com os seus valores, confrontou-se com as necessidades de encarar o futuro enquanto movimento social e de perpetuação da sua ação no tempo: 
Não [havia nenhum tipo de liderança], obviamente havia pessoas que tinham, eu não digo mais disponibilidade de tempo, mas que se disponibilizaram mais em termos da sua vida e do seu tempo para isso. E, obviamente, estavam mais presentes, sabiam mais do assunto, tinham conhecimentos mais técnicos desta ou daquela área, estavam mais ao corrente do que se estava a passar, e obviamente tiveram uma posição mais preponderante, sim (entrev. a Teresa S.).

Ela [liderança] nunca foi discutida. Eu acho que as coisas aconteciam por acontecer, e aconteciam de uma forma espontânea e quase natural. As pessoas agiam um pouco de acordo com aquilo que podiam dar à plataforma (entrev. a Miguel D.).

Neste plano, e em relação à estrutura e à liderança, o movimento identifica-se com o perfil considerado de "militante", quando reportado à tipologia das iniciativas de desenvolvimento local apresentada por A. Monteiro (2004b). Um tal perfil assenta em valores herdados dos movimentos sociais dos anos 1960 e 1970, confronta-se ideologicamente com o modelo dominante de governança e recusa modelos de gestão organizacional tradicionais, preferindo uma orientação de acordo com princípios de solidariedade, democracia e autonomia, operacionalizado por contribuições de cada participante para a ação (MONTEIRO, 2004b, p. 10-11). Por força destas características e tendo em conta outras experiências, como a do movimento espanhol Salvem El Cabanyal, em Valência, são a liderança e a existência de uma estrutura que se constituem como os fatores de sucesso de um movimento. Emílio Martinez, atual dirigente do referido movimento, afirma que "necessariamente deben haber lideres reconocibles por todos" (entrevista a Emílio M.) e aponta como fatores determinantes para a força e o dinamismo do movimento a existência de "objetivos, liderazgo, creatividad, empatia" (entrevista a Emílio M.).

No plano pessoal: Luís S. e Miguel D., dois elementos fundadores, considerados mais ativos do movimento, foram pais pela primeira vez e um destes elementos passou a residir na cidade do Porto, por razões familiares. Estas alterações nas vidas pessoais afetaram as suas disponibilidades, alteraram as prioridades e o grau emocional que os matinham na ação coletiva, influenciando a energia ativa do movimento.

Pelas razões anteriormente apresentadas, a relação entre o movimento e a ameaça sofreu também uma mutação significativa. Os elementos da Plataforma do Choupal sentem que esse ainda está em risco; apontam os fenómenos acima descritos como causas de estagnação da ação do movimento, embora nunca o considerem extinto; e assumem uma desmobilização dos atores sociais. Miguel D., fundador do movimento, reconhece que "Agora, neste momento, a plataforma, objetivamente, está parada" (entrevista a Miguel D.). Segundo os fundadores do movimento, deve-se isto ao cansaço acumulado, e ao ritmo das vidas pessoais e profissionais dos elementos do movimento. Estes e outros atores confirmam:

A minha explicação para isso é muito simples, é que de facto a ameaça deixou de existir e portanto as pessoas relaxaram. Verdadeiramente, aquilo que é importante aqui é isto: a ameaça real e iminente é retirada, o movimento enfraquece (entrev. a Luís S.).

[...] a intensidade da luta diminui imenso. Diminuiu imenso por vários fatores: um foi precisamente a anulação do concurso, a perceção de que começámos a ganhar, de que do 
MONTEIRO, A. A.; MONTEZ, M. M. Sentidos de mobilização e de desmobilização...

outro lado havia uma fraqueza que era a fraqueza financeira, que possivelmente não haveria dinheiro para realizar a obra e acho que foi sobretudo por essa via que se deu alguma desmobilização da plataforma (entrev. a Miguel D.).

Os fatores externos é que determinavam se precisávamos de nos mexermos mais ou não, que aquilo não é nenhum grupo profissional [...]. Quando a ameaça se encontrava mais próxima, a perceção da ameaça era mais clara e a sensação de risco era maior (entrev. a Teresa S.).

\section{Pistas e hipoteses}

Partindo da análise efetuada sobre o percurso da ação coletiva da Plataforma do Choupal, no qual ressalta a relação radical entre ação e desmobilização, apresentam-se articuladamente pistas e hipóteses que podem contribuir para a compreensão deste fenómeno.

A ação coletiva apresentada parte da tensão existente entre os movimentos sociais e a democracia (PEREIRA, 2012), e assenta num conflito em torno de modelos de compreensão do conceito de desenvolvimento. É notória a preocupação do movimento com práticas integrantes de um paradigma de desenvolvimento assente em princípios de sustentabilidade e democracia: por um lado, a valorização do debate e da participação na tomada de decisão; por outro, a contestação a um modelo político obscuro que atende a interesses financeiros privados mais do que aos padrões atuais de qualidade de vida e de sustentabilidade ambiental e social. Contudo, tendo em conta os indícios de uma falta de projeto e de liderança assumida no grupo, e os testemunhos que apontam para a existência de motivações orientadas por protagonismos políticos e pessoais, observam-se na Plataforma do Choupal discrepâncias entre as práticas de gestão do grupo e o modelo de governança que contestam. Torna-se difusa a coerência entre o paradigma de desenvolvimento de referência e os valores e práticas que se the atribuem, complexificando a compreensão da ação coletiva enquanto ação concreta contra uma ameaça portadora de valores antagónicos. É possível que estas características determinem um nível de organicidade e de uma capacidade de ação ao longo do tempo, insuficientes para que uma ação coletiva desta natureza se transforme, como apontam alguns autores, em movimento social (CHINCHILA, 2006). Com feito, fatores como a identidade coletiva, a identificação de um adversário, a definição de um propósito e um objeto concreto posto em causa no conflito (MELUCCI, 1996; ESTANQUE, 1999) são essenciais para que a mobilização ocorra com sucesso.

Outra pista para a compreensão da ação coletiva prende-se com a perceção de risco e de perigo, e sua relação com a ação. Como se verificou no percurso do movimento cívico, o momento de maior ação coincide com o momento de maior intensidade da ameaça. A partir daqui levanta-se a hipótese de existência de uma dinâmica assente na relação de proximidade entre a ameaça e as perceções de risco e perigo sentidas pelos sujeitos, em impulsos de ordem emocional mais do que de ordem racional. Pela proximidade ou afastamento em relação aos bens que os sujeitos usufruem, a ameaça alcança, neste caso, um papel extremamente relevante: quando próxima, intensifica a perceção de risco e de perigo, sentidos coletivamente, e assim potencializa a mobilização de recursos e o despoletar da ação coletiva, no que denominamos "sentido ascendente"; quando distante, alivia o 
sentimento de risco e perigo do coletivo, e influencia a desmobilização da ação coletiva, no que denominamos de "sentido descendente". A Figura 1 representa graficamente esta dinâmica:

Figura 1

\section{Sentidos da ação coletiva}

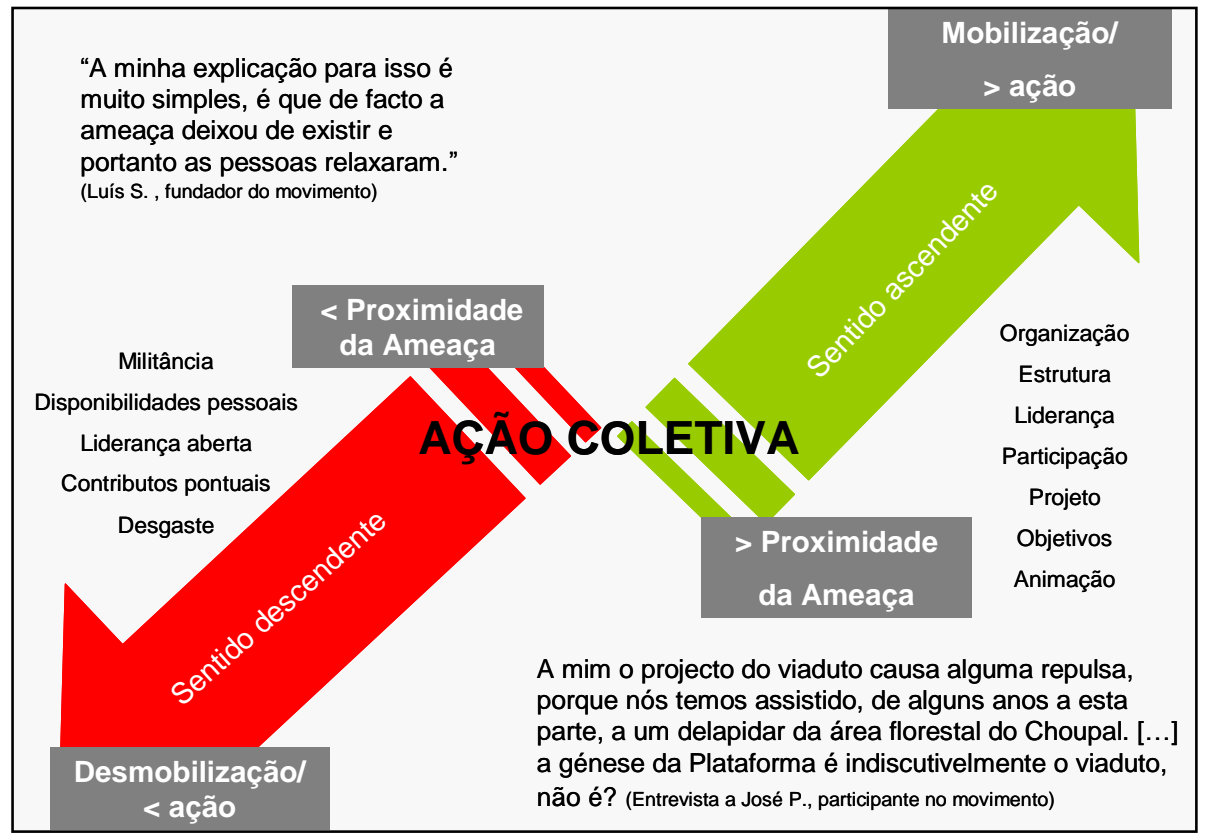

Fonte: Elaboração própria com base nos dados recolhidos.

Esta hipótese ilustra-se pela comparação entre a desmobilização da Plataforma do Choupal, após dois anos de ação, com a perpetuação de 13 anos verificada no movimento Salvem El Cabanyal face à constante ameaça de demolição do bairro pelas autoridades valencianas. Segundo o dirigente, a ação do seu movimento mantém-se "porque el problema sigue estando". Conforme a sua experiência, a ameaça influi no dinamismo da ação no sentido em que "cuanto mayor es la amenaza hay una mayor implicación, una mayor predisposición a colaborar con las propuestas que surjan y hay una implicación más personal" (entrevista a Emílio M.).

\section{Notas Conclusivas}

O estudo de caso aqui apresentado tinha como objetivo primeiro o de compreender a ação coletiva de um movimento cívico considerado como pequeno grupo e de que forma a sua ação contribuía para a produção de um movimento social transformador da sociedade. A procura de razões para a ação coletiva deste movimento, através da investigação, provocou, por sua vez, o efeito inesperado de produção de uma reflexão sobre a ação por parte dos elementos mais ativos, numa altura em que o 
MONTEIRO, A. A.; MONTEZ, M. M. Sentidos de mobilização e de desmobilização...

movimento se desativava. O testemunho de cada sujeito da ação, dado em entrevistas, a formulação de hipóteses e a partilha de resultados com os seus elementos têm conduzido a uma vontade de reativação da ação do movimento, manifestada por alguns dos seus fundadores. A abordagem etnográfica e indutiva em que assentou o estudo de caso trouxe ganhos específicos na relação entre o investigador e os atores sociais, permitiu uma partilha na compreensão dos fenómenos aqui expostos e desvendou o carácter emocional e subjetivo dos testemunhos, tão relevante para a produção de hipóteses. Foi motivante no sentido em que a investigação decorreu de um posicionamento também militante, sob a responsabilidade de compreender o percurso crítico desta ação coletiva e, talvez, também de a reavivar. Contudo, constatou-se que um movimento cívico não se sustenta pela condição meramente militante dos seus elementos. Ele necessita de um projeto a médio-longo prazo e de uma ambição que se operacionalize através de ações estruturadas, e para os quais faz sentido o recurso a metodologias sociais específicas, como a animação sociocultural. Como tal, este artigo enceta um possível ponto de partida para uma investigação centrada no papel dos animadores e animadoras socioculturais na ação coletiva, e do seu contributo na geração de movimentos sociais contemporâneos, tendo como pressuposto a hipótese levantada em torno da dinâmica de ação e de desmobilização da mesma e o carácter militante desta metodologia social.

Apesar do sentimento de afastamento e da efetiva desmobilização do movimento, a ameaça persiste sobre o Choupal, e sobre outros bens públicos que se encontram na encruzilhada entre os discursos e as ações políticas, suportadas por ilusões populistas e modelos de desenvolvimento dificilmente sustentáveis. Com eles, estão em risco também práticas, direitos e liberdades conseguidas por anteriores ações e movimentos. Por isso, a ação coletiva é um campo de estudo de atual importância científica, social e política. Compreender a subjetividade inerente à ação coletiva, assim como a dinâmica dos seus dois sentidos, é ajudar a garantir uma ação coletiva que comprometa cada sujeito com a ação transformadora da sociedade, à escala local e global, na contestação dos poderes dominantes. Ao mesmo tempo, conquistam-se novas soluções de governança e de exercício da cidadania.

\section{Referências Bibliográficas}

ALVESSON, M.; SKöLDBERG, K. Reflexive methodology: new vistas for qualitative research. London: Sage Publications, 2000.

Arendt, H. A condição humana. Lisboa: Relógio de Água, 2001.

BECK, U. Risk society. towards a new modernity. New Delhi: Sage, 1992.

BeCK, U.; GIDDEnS, A.; LASH, S. Modernização reflexiva. Política, tradição e estética no mundo moderno. Oeiras: Celta Editora, 2000.

CHINCHILA, M. "Acción colectiva e intervención professional del trabajo social: límites y possibilidades para la construcción de ciudadanía”. Katálysis, Florianópolis, vol. 9, n² 2, p. 158-1665, jul.·dez. 2006.

Demazière, D.; Dubar, C. Analyser les entretiens biographiques: l'exemple de récits d'insertion. Paris: Éditions Nathan, 1997

DRURY, J.; REICHER, S. "Collective psychological empowerment as a model of social change: researching crowds and power". Journal of Social Issues, vol. 65, n 4, p. 707-725, December 2009. 
ESTANQUE, E. "Aç̧ão colectiva, comunidade e movimentos sociais: para um estudo dos movimentos de protesto público". Revista Crítica de Ciências Sociais, Coimbra, n 55, p. 85·111, nov. 1999.

FERREIRA, F. I. "Ambiguidades das políticas sociais contemporâneas: a participação sem participantes". In: Actas do VIII Congresso Luso-Afro-Brasileiro de Ciências Sociais - Centro de Estudos Sociais da Universidade de Coimbra. Coimbra, set. 2004.

FLAM, H. "Emotional 'Man': I. The emotional 'man' and the problem of collective action". International Sociology, $\mathrm{n}^{\circ} 1, \mathrm{p}$. 39.56, march 1990.

GarRetón, M.A. "La tranformación de la acción colectiva en América Latina". Revista de la Cepal, México, n 76, p. 7-24, abr. 2002.

Goodwin, J.; JASPeR, J. M.; PoletTA, F. Emotional dimensions of social movements. In: SNow, D. A.; Soule, S. A.; KRIESI, H. (eds.). The Blackwell companion to social movements. Victoria: Blackwell Publishing, 2004.

GuerRA, I. "O planeamento estratégico das cidades - organização do espaço e acção colectiva". Revista Cidades e Territórios, Lisboa, $\mathrm{n}^{\circ}$ 1, p. 37.55, dez. 2000

Participação e acção colectiva - interesses, conflitos e consensos. Estoril: Editora Principia, 2006.

JASPER, J. M. "The Emotions of protest: affective and reactive emotions in and around social movements". Sociological Forum, vol. 13, nº 3, p. 397.424, 1998.

$\overline{285 \cdot 303}, 2011$

"Emotions and social movements: twenty years of theory and research". Annual Review of Sociology, $n^{\circ} 37, p$

LAMmerinK, M.; BURY, P.; Bolt, E. "An introduction to participatory action development". PLA Notes, vol. 35, p. 29-33, 1999.

MelucCl, A. Challenging codes: collective action in the information age. Cambridge: Press Syndicate of the University of Cambridge, 1996.

MendonçA, R. "Reconhecimento e (qual?) deliberação”. Opinião Pública, Campinas, vol. 17, nº 1, p. 206-227, jun. 2011.

MontelRo, A. Associativismo e novos laços sociais. Coimbra: Quarteto, 2004a.

"O que as move? Ensaio sobre a tipologia das iniciativas de desenvolvimento local (idl) e as suas orientações na/para a acção". In: Actas dos ateliers do V Congresso Português de Sociologia Sociedades Contemporâneas: Reflexividade e Acção, Coimbra, p. 1-12, 2004b.

OLson, M. A lógica da acção colectiva: bens públicos e teoria dos grupos. Oeiras: Celta Editora. 1998

PARDO, M. "Sociologie et risque: nouveaux éclairages sur les facteurs sociaux et la participation". MANA - Revue de Sociologie et d'Anthropologie, $\mathrm{n}^{\circ}$ 10-11, p. 285-305, 2002.

PARSONS, T.; SHILS, E. Towards a general theory of action - theoretical foundations for the social sciences. New Brunswick/Londres: Transaction Publishers, 2007.

PereIRA, M. "Movimentos sociais e democracia: a tensão necessária". Opinião Pública, Campinas, vol. 18, n 1, p. 68.87, jun. 2012.

QUIRós, J. "Política e economia na ação coletiva: uma crítica etnográfica às premissas dicotómicas". MANA, Rio de Janeiro, vol. 15, n 1, p. 127-153, abr. 2009.

ReBelo, F. Riscos naturais e acção antrópica: estudos e reflexões. Coimbra: Imprensa da Universidade de Coimbra, 2003.

Geografia física e riscos naturais. Coimbra: Imprensa da Universidade de Coimbra, 2010.

SABUCEDo, J. M., et al. "Emotions, ideology and collective action". Universitas Psychologica, Bogotá, vol. 10, nº 1, p. 27. 34, Enero-Abril, 2010. 
SANToS, B. S. Democratizar a democracia: os caminhos da democracia participativa. Porto: Edições Afrontamento, 2001.

Tholts, P. A. "The sociology of the emotions". Annual Review of Sociology, n 15, p. 307-342, 1989.

TILLY, C. La France conteste: de 1600 à nos jours. Paris, Fayard, 1986.

TOURAINE, A. O retorno do actor: ensaio sobre sociologia. Lisboa: Instituto Piaget, 1996.

Van Zomeran, M.; IYer, A. "Introduction to the social and psychological dynamics of collective action". Journal of Social Issues, vol. 65, n 4, p. 645.660, December, 2009.

Alcides A. Monteiro - alcidesmonteiro@yahoo.com

Mário Miguel Montez ·montez.mario@gmail.com; montez@esec.pt

Submetido à publicação em dezembro de 2012.

Versão final aprovada em setembro de 2014. 